\title{
Direct Measurement of Lateral Molecular Diffusivity on the Surface of Supersaturated Amorphous Solid Dispersions by Atomic Force Microscopy
}

\author{
Bannow, Jacob; Karl, Maximilian; Larsen, Peter Emil; Hwu, En Te; Rades, Thomas
}

Published in:

Molecular Pharmaceutics

Link to article, DOI:

10.1021/acs.molpharmaceut.0c00176

Publication date:

2020

Document Version

Publisher's PDF, also known as Version of record

Link back to DTU Orbit

Citation (APA):

Bannow, J., Karl, M., Larsen, P. E., Hwu, E. T., \& Rades, T. (2020). Direct Measurement of Lateral Molecular Diffusivity on the Surface of Supersaturated Amorphous Solid Dispersions by Atomic Force Microscopy. Molecular Pharmaceutics, 17(5), 1715-1722. https://doi.org/10.1021/acs.molpharmaceut.0c00176

\section{General rights}

Copyright and moral rights for the publications made accessible in the public portal are retained by the authors and/or other copyright owners and it is a condition of accessing publications that users recognise and abide by the legal requirements associated with these rights.

- Users may download and print one copy of any publication from the public portal for the purpose of private study or research.

- You may not further distribute the material or use it for any profit-making activity or commercial gain

- You may freely distribute the URL identifying the publication in the public portal 


\title{
Direct Measurement of Lateral Molecular Diffusivity on the Surface of Supersaturated Amorphous Solid Dispersions by Atomic Force Microscopy
}

\author{
Jacob Bannow, ${ }^{\S}$ Maximilian Karl, ${ }^{\S}$ Peter Emil Larsen, En Te Hwu, and Thomas Rades*
}

Cite This: https://dx.doi.org/10.1021/acs.molpharmaceut.0c00176

Read Online

ABSTRACT: Quantifying molecular surface diffusivity is of broad interest in many different fields of science and technology. In this study, the method of surface grating decay is utilized to investigate the surface diffusion of practical relevant amorphous solid dispersions of indomethacin and the polymeric excipient Soluplus (a polyvinyl caprolactam-polyvinyl acetate-polyethylene glycol

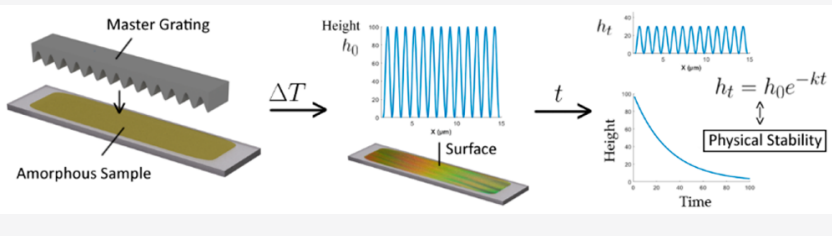
graft copolymer) at various polymer concentrations $(1-20 \% \mathrm{w} /$

w). The study confirms that measuring surface diffusivity below the system's glass transition temperature is possible with a simplified atomic force microscopy setup. Results highlight a striking polymer influence on the surface diffusivity of drug molecules at low polymer concentrations and a turnover point to a polymer dominated diffusion at around three percent (w/w) polymer concentration. The surface diffusion measurements further correlate well with the observed increase in physical stability of the system as measured by X-ray powder diffraction. These findings are of vital interest in both the applied use and fundamental understanding of amorphous solid dispersions.

KEYWORDS: surface mobility, amorphous solid dispersion (ASD), atomic force microscopy (AFM), molecular surface diffusivity, indomethacin, soluplus, grating decay

\section{INTRODUCTION}

Studying the molecular mobility on surfaces is of broad interest in a variety of fields including electronics manufacturing (e.g., for semiconductors ${ }^{1}$ ), catalysis, ${ }^{2}$ crystal growth investigations, ${ }^{3}$ and the formulation of low energy glasses by vapor deposition. $^{4}$ Moreover, in pharmaceutical research and development, surface properties of amorphous formulations are of interest since the transformation of crystalline small organic drug compounds into their amorphous form has gained significant attention over the last decades. ${ }^{5,6}$ Amorphous solids are characterized by their high internal energy and lack in long-range molecular order leading to an increased molecular mobility, which often results in a desired improvement in apparent solubility and dissolution rate, compared to their crystalline counterparts. However, these advantages come at the cost of reduced physical stability, which might prevent the marketing of amorphous drug formulations.?

The high molecular mobility in these solids not only promotes relaxation toward the thermodynamic equilibrium but also enables a fast lateral diffusion of molecules on amorphous surfaces. ${ }^{8}$ With the aim of preserving the abovementioned beneficial properties of amorphous compounds, different stabilization techniques have been established. ${ }^{9-11}$ Especially the dispersion of amorphous drugs into a polymeric matrix to form an amorphous solid dispersion (ASD) has found widespread use. The polymer and drug form a homogeneous blend, stabilizing the amorphous drug during storage. To keep the formulation thermodynamically stable, the drug concentration must be kept below its equilibrium solubility in the polymeric matrix, which often results in low drug loadings. ${ }^{12}$ However, studies have demonstrated the ability of supersaturated ASDs to remain physically stable over time frames that would satisfy shelf life requirements. ${ }^{13}$ The stabilizing effect of polymers might be attributed to an increase of the glass transition temperature $\left(T_{\mathrm{g}}\right)$ of the formed ASD, which increases the needed energy input for the amorphous drug to recrystallize (antiplasticization effect). ${ }^{14}$ In contrast, cases have been observed where the physical stability of the ASD could be improved without a noticeable increase of the $T_{\mathrm{g}}{ }^{15}$ In these cases, specific drug-polymer interaction, such as the formation of hydrogen bonds or ionic interactions, were attributed to stabilize the amorphous material, without a special focus on surface properties. ${ }^{16}$ To expand knowledge on the mechanism behind the stabilization effect of polymeric excipients on the physical stability of supersaturated ASDs, an investigation of surface mobility, for example, by the in-plane

Received: February 18, 2020

Revised: March 24, 2020

Accepted: March 24, 2020

Published: March 24, 2020 
self-diffusion coefficient $D_{s}$, of the drug-polymer mixtures is desired.

Measuring $D_{s}$ has been a subject of scientific interest since the $1920 \mathrm{~s}^{17}$ The $D_{s}$ has since been determined for metals and semiconductors as well as for silicon. ${ }^{18}$ However, there is only very limited data available on amorphous small organic molecules or polymers. ${ }^{17,19}$ In 2006, Mapes et al. measured the self-diffusion of the organic amorphous model compound $o$-terphenyl (OTP) with a bilayer surface desorption technique in the supercooled regime and found a deviation from the Stokes-Einstein prediction upon approaching $T_{\mathrm{g}}{ }^{20}$ The method of surface grating decay, where an initially corrugated surface flattens over time, was first used by $\mathrm{Yu}$ and co-workers to report the surface self-diffusion of glassy indomethacin below its glass transition temperature. ${ }^{8}$ This group has since almost exclusively pioneered the work on organic amorphous compounds with further measurements on nifedipine, ${ }^{21}$ polyalcohols, ${ }^{22}$ griseofulvin, ${ }^{23}$ and polystyrene. ${ }^{24}$ To this date, only a single study on a two component system, an amorphous mixture of OTP with $1 \%(\mathrm{w} / \mathrm{w})$ polystyrene, exists in the literature. ${ }^{25}$ All of the studies above report a surface diffusion many magnitudes faster than the respective bulk diffusion.

With our current work, we are extending the measurement of surface mobility with atomic force microscopy (AFM) to systems with more practical relevance. An aim of the study is to introduce the method of surface grating decay based on Mullin's model (see below) to the applied physico-chemist with demonstrating surface mobility measurements of an amorphous solid dispersion of indomethacin and the commonly used pharmaceutical excipient Soluplus at various polymer concentrations. Our study highlights that a direct measurement of the surface mobility below the glass transition of a practical relevant system under realistic storage conditions is possible with a cost-effective experimental setup. The results further highlight a strong correlation to physical stability and offer a possible mechanistic explanation for the observed crystallization tendencies as well as a striking polymer influence on the surface diffusivity of drug molecules already at low polymer concentrations. This information is of vital interest for further applied development and fundamental understanding of amorphous formulations, for example, in pharmaceutical preclinical development.

\section{EXPERIMENTAL SECTION}

Mullins' Model and Experimental Considerations. The theoretical framework to describe the evolution of a sinusoidal surface $W$ over time $t$ is given by Mullins, ${ }^{26}$ in the integral form:

$$
W(t)=W(t=0) \mathrm{e}^{-K t}
$$

According to Mullins, the decay is driven by viscous flow (Vis), evaporation-condensation (E1 and $E 2$ ), bulk diffusion $(B u)$, and surface $(S)$ diffusion. The decay constant $K$ can be expressed as a combination of the individual processes, where $\lambda$ is the wavelength of the sinusoidal grating:

$$
\begin{aligned}
K= & k_{V i s}\left(\frac{2 \pi}{\lambda}\right)^{1}+k_{E 1}\left(\frac{2 \pi}{\lambda}\right)^{2}+k_{E 2}\left(\frac{2 \pi}{\lambda}\right)^{3}+k_{B u}\left(\frac{2 \pi}{\lambda}\right)^{3}+k_{S} \\
& \left(\frac{2 \pi}{\lambda}\right)^{4}
\end{aligned}
$$

The surface self-diffusion coefficient $D_{s}$ is related to $k_{s}$ by eq 3 , where $\gamma$ is the surface free energy, $\Omega$ is the molar volume, $v$ is the aerial density, $k_{b}$ is the Boltzmann constant, and $T$ is the temperature:

$$
k_{s}=\frac{D_{s} \gamma \Omega^{2} v}{k_{b} T}
$$

The individual components of the other processes are further described in the Supporting Information. It can be seen from eq 2 that each process has its own wavelength dependency. This fact is utilized to confirm the underlying decay mechanism experimentally. The validity of Mullin's model, including the presence of a mobile surface layer, has further been confirmed experimentally and theoretically. ${ }^{27}$ It should be noted that the gratings used in this study have an amplitude/ wavelength ratio of around 0.1 . Therefore, the samples fall into the small-aspect ratio approximation, a prerequisite for the application of Mullins' model. ${ }^{28}$ Moreover, the applied method is performed on thick samples (film thickness/grating's wavelength $\gg 1$ ). Hence, substrate effects are neglected, and the underlying theoretical framework differs from other techniques, such as stepped film methods, which might be performed on thick or thin samples. ${ }^{29}$

Materials and Sample Preparation. The amorphous films were produced using a solvent evaporation method previously described by Knopp et al. with minor modifications. ${ }^{30}$ As a first step, indomethacin (IMC, Tokyo Chemical Industry, Tokyo, Japan) and the corresponding amount of Soluplus (SP), a polyvinyl caprolactam-polyvinyl acetatepolyethylene glycol graft copolymer (BASF, Ludwigshafen, Germany), were dissolved in a mixture of aceton:ethanol $(80: 20 \mathrm{~V} / \mathrm{V})$ generating a clear and particle free solution $(c=$ $100 \mathrm{mg} / \mathrm{mL})$. Approximately $50 \mu \mathrm{L}$ was pipetted on a microscopic cover glass, placed on a hot plate. The cover glass was heated to $170{ }^{\circ} \mathrm{C}\left(15^{\circ} \mathrm{C}\right.$ above the melting point of $\mathrm{IMC}$ ) for $6 \mathrm{~min}$ to ensure a complete evaporation of the organic solvent and melting of crystalline IMC. To generate flat films, a second cover glass was gently pressed on the liquid sample surface. The samples that were sandwiched between two cover glasses were subsequently placed on a metal block for cooling, which resulted in amorphous films of an average thickness of $9 \mu \mathrm{m}$ (see Supporting Information, Figure S1). After the removal of one cover glass, the amorphous films were reheated to $70{ }^{\circ} \mathrm{C}\left(T_{\mathrm{g}}\right.$ of IMC $\left.+25{ }^{\circ} \mathrm{C}\right)$ to enable the imprinting on the exposed amorphous surface with gold coated polymer grating films, which were slowly detached after equilibration to room temperature. Gratings for the imprinting on the amorphous surfaces with a grating wavelength of 1500 and $740 \mathrm{~nm}$ were derived from conventional CDs and DVDs, respectively. Glass diffraction gratings with a wavelength of 833 $\mathrm{nm}$ were obtained from Edmund Optics Ltd. (Nether Poppleton, UK), and grating foils with a wavelength of 1000 and $2000 \mathrm{~nm}$ were obtained from Rainbow Scientific Inc. (Windsor, CT, USA). To produce suitable gratings for the imprinting process, the UV-curing polymer NOA 65 (Norland Products Inc., Cranbury, NJ, USA) was used to prepare polymer films of the CD, DVD, and glass grating masters. All gratings were sputter coated with gold (Cressington 108 auto, Cressington Scientific Instruments, Watford, UK) prior to imprinting.

Instrumentation and Methods. AFM measurements (AC mode) were performed on the Strømlinet Advanced 

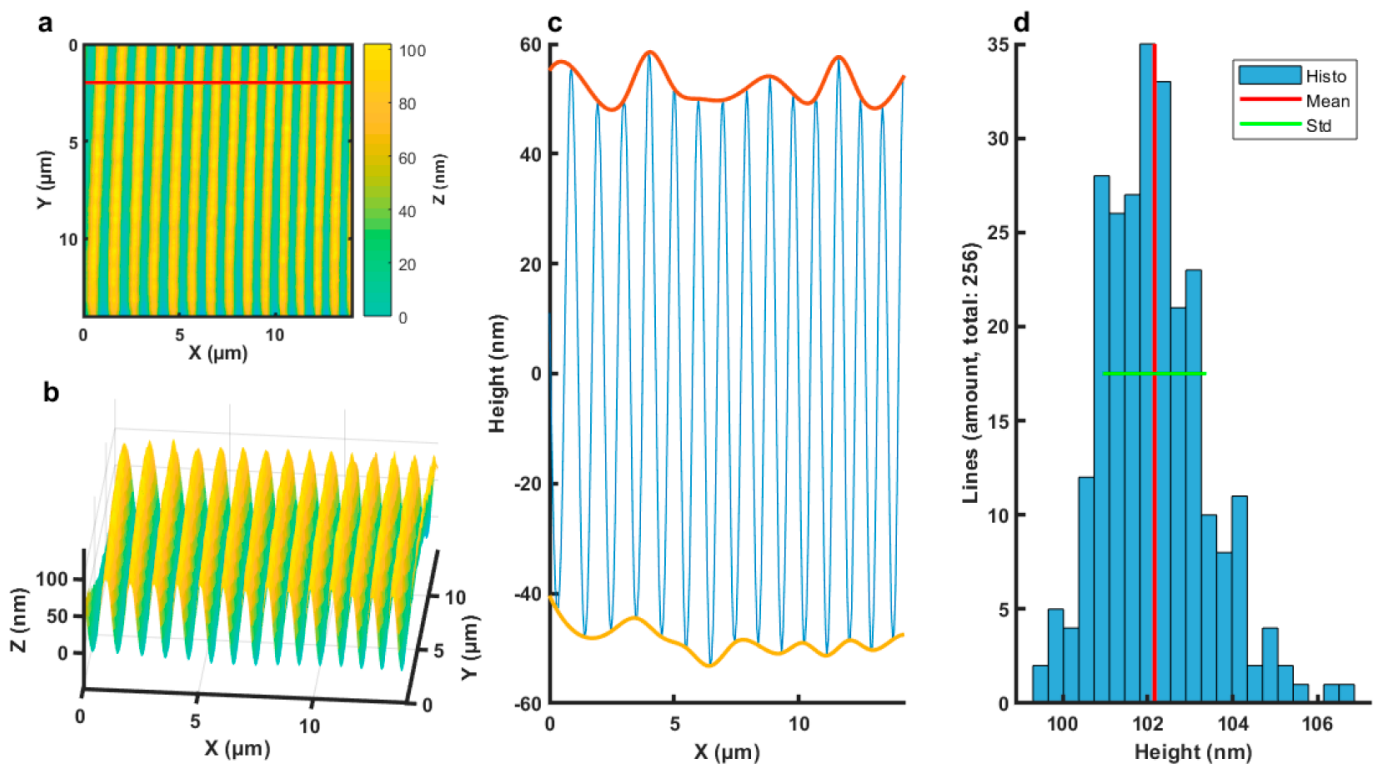

Figure 1. (a) Topographic AFM picture of a corrugated amorphous indomethacin surface (grating wavelength $1000 \mathrm{~nm}$ ). (b) Surface plot of panel a at a tilt angle. (c) Profile of the red line shown in panel a with analytical envelopes. (d) Height histogram of all lines from panel a with mean (red vertical) and standard deviation (green horizontal).

AFM system (Strømlinet Nano Inc., Taipei, Taiwan), a miniaturized atomic force microscope. AFM probes (NSC35/AL BS) were obtained from MIKROMASCH EUROPE (Wetzlar, Germany) and $130 \mu \mathrm{m}$ long cantilevers with a resonance frequency of $150 \mathrm{kHz}$ and a force constant of $\sim 5 \mathrm{~N} / \mathrm{m}$ were used. The instrument was XYZ-calibrated with a calibration sample (TGXYZ02) from the same manufacturer.

An offline measurement method was used. The samples were stored in a desiccator at $30{ }^{\circ} \mathrm{C}\left( \pm 1{ }^{\circ} \mathrm{C}\right)$ and $32 \% \mathrm{rH}$ (adjusted with a saturated magnesium chloride solution) and measured at ambient conditions. The temperature deviation from storage conditions during measurement was assumed to be negligible as the time frame of the measurements is very short $(6 \mathrm{~min})$ compared to the time frame of the full decay process (hours to several weeks).

Modulated differential scanning calorimetry (mDSC) was performed using a Discovery differential scanning calorimeter (TA Instruments, New Castle, DE, United States) and analyzed with TRIOS software (TA Instruments). To mimic the above-described sample preparation, sample solutions were pipetted into Tzero aluminum pans and sealed with pierced Tzero hermetic lids after the solvent was evaporated at $170{ }^{\circ} \mathrm{C}$ (dry sample mass of 3-5 mg). All measurements were carried out at a starting temperature of $-10{ }^{\circ} \mathrm{C}$ using a heating rate of $3{ }^{\circ} \mathrm{C} / \mathrm{min}$ with a temperature amplitude of $1{ }^{\circ} \mathrm{C}$ and a period of $40 \mathrm{~s}$ under a nitrogen gas flow of $50 \mathrm{~mL} / \mathrm{min}$. To predict the solubility of IMC in SP, the melting point depression method as previously described by Blaabjerg et al. was utilized. ${ }^{31}$ Briefly, physical mixtures of IMC and SP (80-90\% (w/w) IMC) were weighed into Tzero pans and sealed with a pierced hermetic lid. The samples were heated at a rate of $1^{\circ} \mathrm{C} / \mathrm{min}$ from 80 to $165{ }^{\circ} \mathrm{C}$ using the same Discovery differential scanning calorimeter as previously mentioned. Subsequently, the detected melting point onsets of IMC were fitted with the Flory-Huggins model ${ }^{30}$ to determine the solubility of IMC in SP, as further described in the Supporting Information Section 3.1 .
X-ray powder diffraction (XRPD) measurements were performed using a X'Pert PRO diffractometer (PANalytical, The Netherlands) with $\mathrm{Cu} \mathrm{K} \alpha$ radiation $(\lambda=1.542 \AA$, current $40 \mathrm{~mA}$, voltage $45 \mathrm{kV}$ ), operated in reflection mode. To assess the physical stability of neat amorphous IMC and supersaturated ASDs, amorphous films (see Materials and Sample Preparation) were powdered using a mortar and pestle and stored under the same conditions as used for the AFM measurements $\left(30{ }^{\circ} \mathrm{C}, 32 \% \mathrm{rH}\right)$. The powdered amorphous samples were placed on aluminum sample holders and scanned from 5 to $35^{\circ}(2 \theta)$ using a scan speed $0.067335^{\circ} \mathrm{s}^{-1}$ and step size of $0.0262606^{\circ}(2 \theta)$. The same powdered samples were also analyzed using Fourier-transform infrared spectroscopy (FTIR). Spectra were collected from 600 to $4000 \mathrm{~cm}^{-1}$ (128 scans, with a resolution of $2 \mathrm{~cm}^{-1}$ ) using a Bomem IR spectrometer (Bomem, Quebec, Canada) operated in the total reflectance mode (using an attenuated total reflectance accessory).

Scanning electron microscopy (SEM) was used to determine the thickness of amorphous films. Images of cross-sections were acquired using a Hitachi TM3030 tabletop microscope (Hitachi, Chiyoda, Japan) and analyzed utilizing Gwyddion software v.2.55 (Czech Metrology Institute, Jihlava, Czech Republic).

AFM Data Analysis. The data analysis process was performed and automized in MATLAB R2019a as shown in Figure 1. After the measurement was finished, each measurement line (perpendicular to the grating) of the AFM picture (see Figure 1a,b) was detrended, and the smoothed analytical envelopes were obtained from a Hilbert transform (see Figure 1c), which was in turn obtained by an n-point Fourier transform. The height information on the line was obtained by subtracting the lower from the upper envelope. The average grating height of the picture was calculated from every line in the respective picture (see Figure 1d).

As described previously, ${ }^{8,25}$ the height information for several pictures over the measurement time is subsequently fitted either with a single exponential decay function or with a 
stretched exponential (see also Figure 5 below) to obtain the decay constant $K$. Obtained $\log K$ values from either fit did not differ significantly (difference $<0.1 \mathrm{~s}^{-1}$ ) and $\log K$ values shown in Figure 4 and Figure 6 are from the stretched exponential fit.

\section{RESULTS AND DISCUSSION}

To characterize the solid state properties of the prepared ASDs, as well as neat amorphous IMC and SP, FTIR and mDSC analyses were performed (see Figure 2).

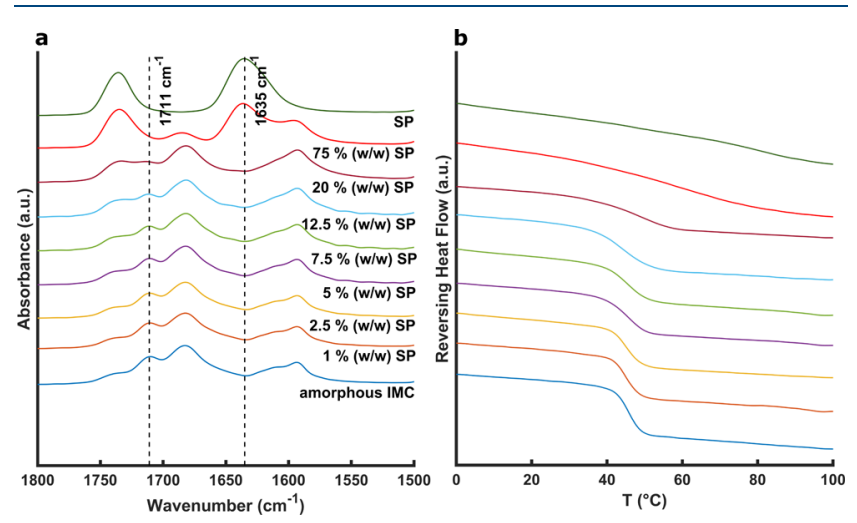

Figure 2. (a) FTIR spectra of neat amorphous IMC, SP, and amorphous IMC containing different concentrations of Soluplus. The carbonyl stretching of a cyclic dimer of amorphous IMC at $1711 \mathrm{~cm}^{-1}$ and the tertiary amide carbonyl stretching of SP at $1635 \mathrm{~cm}^{-1}$ is marked for better visibility. (b) Reversing heat flow signal of the same samples.

The existence and extent of intermolecular hydrogen bonds have been shown to play an important role for the molecular mobility on amorphous surfaces as well as for the physical stabilization of ASDs. ${ }^{32,33}$

Because of the ability of IMC to act as both a hydrogen bond acceptor (carboxylic acid and amid) and donor (carboxylic acid), the formation of hydrogen bonds between IMC molecules as well as between IMC and the acceptor groups of SP (tertiary amide and carboxylic ester) was suspected (see Figure 3 for chemical structures).

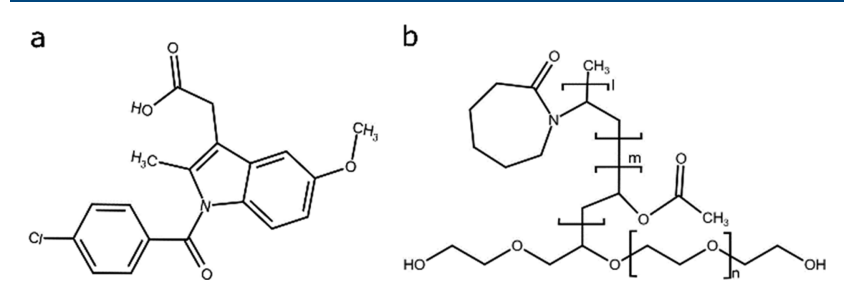

Figure 3. (a) Structure of indomethacin. (b) Structure of polyvinyl caprolactam-polyvinyl acetate-polyethylene glycol graft copolymer (Soluplus).

The characteristic absorption bands in the carbonyl stretching region between $1500 \mathrm{~cm}^{-1}$ and $1800 \mathrm{~cm}^{-1}$ for all samples are shown in Figure 2a (see Supporting Information Figure S2 for complete spectra).

Neat amorphous IMC showed characteristic strong absorption bands at $1711 \mathrm{~cm}^{-1}$ (asymmetric acid $\mathrm{C}=\mathrm{O}$ stretching of a cyclic dimer), $1684 \mathrm{~cm}^{-1}$ (benzoyl $\mathrm{C}=\mathrm{O}$ stretching), and a weak shoulder at $1735 \mathrm{~cm}^{-1}$ (non-hydrogen bonded $\mathrm{C}=\mathrm{O}$ stretching). ${ }^{34}$ The FTIR spectrum for neat SP showed two absorption bands in the carbonyl stretching region at $1635 \mathrm{~cm}^{-1}$ (tertiary amide $\mathrm{C}=\mathrm{O}$ stretching) and $1734 \mathrm{~cm}^{-1}$ (ester $\mathrm{C}=\mathrm{O}$ stretching), ${ }^{35}$ respectively. Because of the low amounts of SP present in the analyzed samples, no apparent differences between the spectra of neat IMC and SP spiked samples were observed up to a SP concentration of $7.5 \%(\mathrm{w} /$ $\mathrm{w})$. At a concentration of $12.5 \%(\mathrm{w} / \mathrm{w})$ SP, the absorption band of the asymmetric carbonyl stretch of the cyclic dimer at $1711 \mathrm{~cm}^{-1}$ was less pronounced and ultimately disappeared at a SP concentration of $75 \%(\mathrm{w} / \mathrm{w})$. This indicates the formation of hydrogen bonds between the carboxylic acid of IMC as the donor group with the carbonyl tertiary amide and carbonyl ester groups of SP as the acceptor group. The disruption of the dimeric structure of amorphous IMC due to the formation of hydrogen bonds with a tertiary amid was previously described for ASDs of IMC and polyvinylpyrrolidone (PVP). ${ }^{36,37}$ Additionally, the absorbance from the tertiary amide carbonyl stretching of SP at $1635 \mathrm{~cm}^{-1}$ disappeared when an excess amount of IMC was present (SP concentrations $>20 \%(w / w)$ ), supporting the suggested interactions with the hydrogen bond donor IMC. ${ }^{35}$ The presence of interaction between IMC and SP was further underlined by the obtained negative FloryHuggins interaction parameter $(-8.3 \pm 2.2)$, indicating interaction and miscibility between the two components. The solubility of IMC in SP at $25{ }^{\circ} \mathrm{C}$ was estimated at $29.8 \%$ $(\mathrm{w} / \mathrm{w})$ using the Flory-Huggins model (see Supporting Information).

Figure $2 \mathrm{~b}$ presents the reversing heat flow signal of $\mathrm{mDSC}$ measurements of neat amorphous IMC and SP as well as SP spiked amorphous IMC. For all measured samples, a single glass transition temperature $\left(T_{\mathrm{g}}\right)$ was observed, indicating the formation of a single-phase amorphous solid dispersion. ${ }^{38,39}$ The $T_{\mathrm{g}}$ of neat amorphous IMC $\left(46^{\circ} \mathrm{C}\right)$ and neat SP $\left(77^{\circ} \mathrm{C}\right)$ are in agreement with previously reported values. ${ }^{40,41}$ When spiking amorphous IMC with low amounts of SP, no significant increase of the $T_{\mathrm{g}}$ was detected up to SP concentrations of $20 \%(\mathrm{w} / \mathrm{w})$. ASDs with an SP concentration of $75 \%(w / w)$ resulted in an increase of the $T_{\mathrm{g}}$ to $59{ }^{\circ} \mathrm{C}$, which is lower than the theoretical value of $72{ }^{\circ} \mathrm{C}$, calculated using the Gordon-Taylor equation (see Supporting Information 3.3).

As described above, amorphous IMC is known to be an extensive former of intermolecular hydrogen bonds, which need to be broken to form new bonds between unlike molecules when SP is introduced to the system. The breakdown of intermolecular hydrogen bonds with higher activation energies and the formation of new hydrogen bonds with lower interaction energies are known to lead to lower $T_{\mathrm{g}}$ values than predicted by theories that are based on the free volume theory such as the Gordon-Taylor equation, as potential molecular interactions are not taken into account. $^{42,43}$

To confirm the surface decay mechanism and ensure method validity, measurements of neat IMC were first performed on gratings with different wavelengths. Afterward the ASDs were investigated.

As shown in Figure $4, K$ is proportional to $\lambda^{-4.1}$, which, according to eq 2 , indicates that the mechanism of surface flattening is primarily due to surface diffusion $\left(K \approx \lambda^{-4}\right)$ within an acceptable experimental error.

The same trend for pure IMC was previously shown and further theoretically underlined by Zhu et al.: ${ }^{8}$ owing to the low vapor pressure of IMC, the evaporation-condensation term of eq 2 becomes negligible, and the bulk diffusion is some 


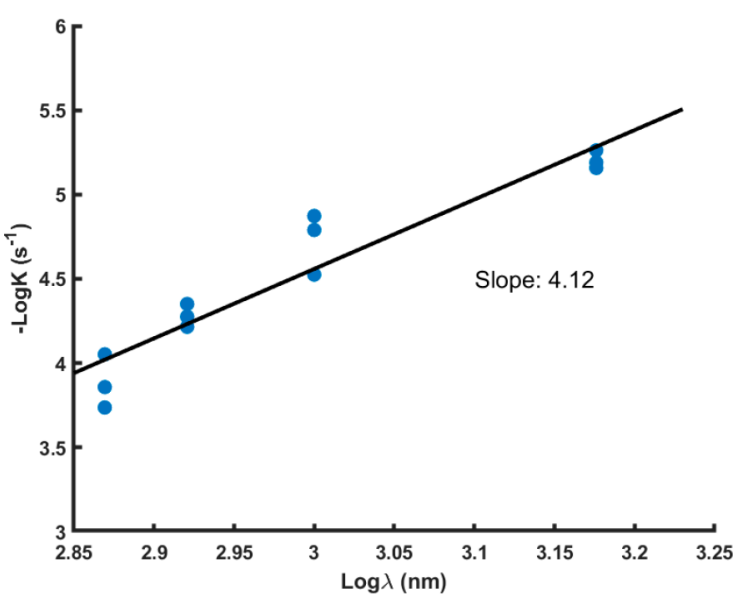

Figure 4. Decay constants of neat IMC as a function of the grating wavelength at $740,833,1000$, and $1500 \mathrm{~nm}$.

orders of magnitude lower than the observed decay constant. ${ }^{44}$ The viscous flow term in eq 2 describes the observed decay only at temperatures above $T_{\mathrm{g}}{ }^{8}$ Therefore, only surface diffusion is left as the driving factor for the flattening process. This allows for a direct calculation of $D_{s}$, which is supplied in the Supporting Information and gives a value of 14.23 for $-\log$ $D_{s}$. Compared with ref 8 , as the only other study available for comparison with IMC, it can be seen that $D_{s}$ falls within the same range, with the difference at a comparable temperature and similar wavelength $(1000 \mathrm{~nm})$ being about a quarter of a magnitude. In contrast and for reference, the bulk diffusion is roughly six magnitudes slower. Note, however, that an exact agreement between this study and ref 8 is not necessarily expected as the sample storage conditions differ (see below).
It is worth noting that we also tried to extend Figure 4 by measuring the surface decay at a wavelength of $2000 \mathrm{~nm}$. However, the higher wavelength extends the decay time toward timeframes ( $>5$ days) where crystallization of neat IMC at $30{ }^{\circ} \mathrm{C}$ is almost inevitable, ${ }^{45}$ preventing proper measurements. An extension to lower wavelengths is further limited due to the limits of the small aspect-ratio approximation (see Experimental Section considerations above).

Figure $5 \mathrm{a}-\mathrm{g}$ present example measurements of the decrease in grating height for neat IMC and the supersaturated ASDs. The blue lines are standard exponential fits $\left(h_{\mathrm{t}}=h_{0} \exp (-k t)\right)$ and the black lines are stretched exponential fits $\left(h_{\mathrm{t}}=h_{0}\right.$ $\left.\exp \left[(-k t)^{\beta}\right]\right)$ to the respective data. While the difference between both fits is comparably small for neat IMC, the fits deviate strongly for the $1 \%(\mathrm{w} / \mathrm{w})$ SP ASDs, which is mainly caused by the data "fronting" at the beginning of the decay, which lowers the $\beta$ value. A similar trend was previously shown when comparing neat OTP samples with $1 \%(\mathrm{w} / \mathrm{w})$ spiked polystyrene samples and qualitatively explained with a heterogeneous decay, where polystyrene molecules enrich on peaks owing to their slower surface mobility. ${ }^{25}$ Our study underlines this observation for $1 \%(\mathrm{w} / \mathrm{w})$ polymer spiked samples. As seen in Figure 5a, a small deviation is already present for neat IMC with $\beta$ values lower than unity. We argue that this deviation is a result of the inherently heterogeneous nature of amorphous IMC (especially compared to OTP). IMC is known to form dimers in the amorphous form (see above). Furthermore, during our study, samples were not stored and measured in dry nitrogen but at a relative humidity of $32 \%$.

The higher humidity introduces water and the possibility of hydrogen bonds between water and IMC molecules on the surface. Hence, the surface diffusion for IMC samples in this study is likely dependent on at least ${ }^{36}$ three surface diffusing
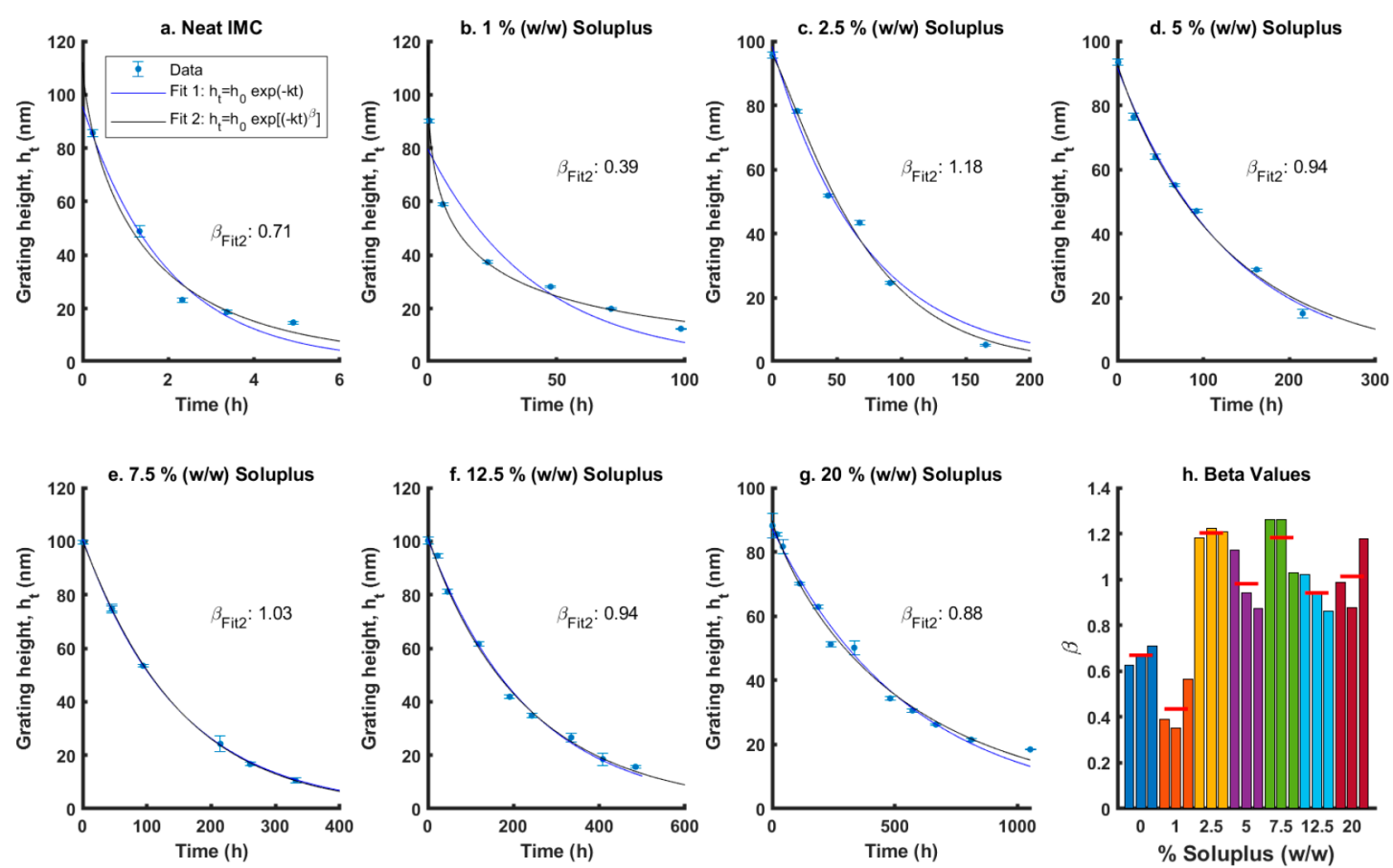

Figure 5. Measurement examples of the surface grating decay at every Soluplus concentration examined in this study. The blue lines represent a standard exponential fit, the black lines an exponential fit with stretching factor $\beta$. The $\beta$ values are further presented in the bar plot on the lower right with the height of the red lines indicating the mean values. 
entities: IMC, water-bound IMC, and IMC-dimers. As described, hydrogen bonding has already been shown to influence surface diffusion, ${ }^{22}$ and differences in the three surface diffusing entities may lead to no mutual diffusion and an overall observed decay differing slightly from a "perfect" exponential, even for pure IMC. With the discussed observations in mind and the fact that IMC crystallizes into different polymorphs at different humidities, ${ }^{46}$ further surface mobility studies under varying humidities may be beneficial.

Interestingly, the $\beta$ values do not decrease with increasing polymer concentration but group around unity for the higher concentration ASDs (see also Figure 5h). This indicates a significant change in surface diffusion.

We hypothesize that, for higher concentration ASDs (which, however, are on an absolute scale still very low \% (w/w) SP concentrations), the surface diffusion is already clearly dominated by the polymer. This observation is further underlined and discussed below by comparing the $\log K$ values of the different formulations. Note that an addition of a single percent polymer increases the surface decay (and hence slows surface diffusion) from about 5 to $100 \mathrm{~h}$ and another one and a half percent to almost $200 \mathrm{~h}$, as seen in Figure $5 \mathrm{a}-\mathrm{c}$.

The significant increase in decay times due to the spiking of amorphous IMC with SP is further reflected in the obtained decay constants $K$. As shown in Figure 6a, the spiking with $1 \%$ $(\mathrm{w} / \mathrm{w})$ and $2.5 \%(\mathrm{w} / \mathrm{w}) \mathrm{SP}$ results in a substantial increase in $-\log K$, which becomes less pronounced when more SP is incorporated in the samples.
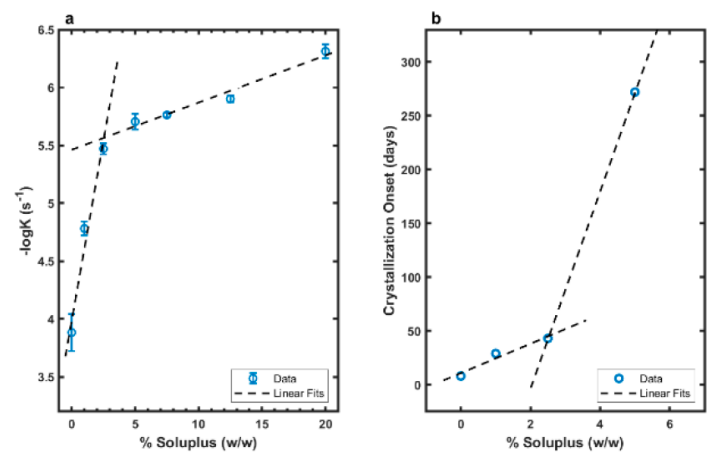

Figure 6. (a) Decay constant $K$ and (b) onset of crystallization as a function of polymer (Soluplus) concentration. Dotted lines are linear fits to the data below and above $2.5 \%(\mathrm{w} / \mathrm{w})$ SP respectively and serve as a guide to the eye.

We therefore suggest a SP concentration between 2.5 and $5 \%(\mathrm{w} / \mathrm{w})$ as the turnover point for SP dominated surface diffusion as reflected by the linear fits. The large differences in the molecular weight of the small organic molecule IMC and the polymer SP are expected to lead to differences in diffusivity between both molecules. We propose that the faster moving IMC molecules may segregate over time, which results in an enrichment of polymer molecules on the amorphous surface, consequently slowing down surface diffusion. However, further experimental evidence is needed to support this hypothesis. The proposed surface enrichment of polymer molecules in spiked amorphous samples was previously discussed by Zhang et $\mathrm{al.}^{25}$ To investigate the influence of polymer spiking on the physical stability of amorphous IMC, powdered films were analyzed using XRPD in regular intervals (see Figure $6 \mathrm{~b}$ and Supporting Information Figure S3 for diffractograms).
Neat amorphous IMC showed an onset of recrystallization after 8 days, which was delayed by the spiking with $2.5 \%$ (w/ w) SP to 43 days. The increase in SP concentration to $5 \%(\mathrm{w} /$ $\mathrm{w}$ ) resulted in a stabilization of the amorphous sample up to 272 days, which presents a remarkable improvement of the physical stability considering the relatively small increase in SP concentration. The characteristic diffraction pattern observed in physically unstable samples suggested recrystallization of amorphous IMC into its alpha polymorph (see Supporting Information Figure S3). Samples containing more than 5\% (w/ w) SP remained amorphous when studied using XRPD to the present day (>10 months).

As low SP concentration did not result in a significant increase of the $T_{g}$, a kinetic stabilization of the amorphous samples due to an antiplasticization effect is not assumed to be a main factor for the physical stabilization. Additionally, low amounts of SP $(<20 \%(w / w))$ did not significantly disrupt the dimer formation of IMC molecules (see Figure $2 \mathrm{a}$ ), which is a crucial component for the inhibition of IMC recrystallization. ${ }^{36}$ In contrast, the previously discussed change to a polymer dominated surface diffusion at SP concentrations of around 2.5 to $5 \%(\mathrm{w} / \mathrm{w})$ correlates well with the observed increase in physical stability at similar concentrations. We therefore suspect a surface enrichment of SP molecules as an important factor for the stabilization of the investigated amorphous IMC samples. Additionally, it has previously been shown that a fast crystal growth at free surfaces further induces bulk crystallization through the creation of voids and new surfaces, ${ }^{47}$ underlining the importance of surface crystallization for the overall physical stability of amorphous particles.

In light of the observed strong correlation with physical stability, it is further noteworthy to mention that Kissi et al. ${ }^{48}$ demonstrated that a major predictive parameter for the recrystallization of neat amorphous drugs is local mobility (in the bulk), more specifically, the $\beta$ relaxation process. Moreover, Capaccioli et al. $^{27}$ presented a mechanistic justification, including a quantitative explanation, for the increase in molecular diffusion at the surface, based on the coupling model (CM) and the corresponding calculation of the primitive relaxation time $\tau_{0}$, as well as its difference to the bulk relaxation $\tau_{\alpha}$. The difference is roughly on the same order of magnitude as the difference between surface and bulk relaxation, and hence, $\tau_{0}$ seems to correlate well with surface diffusion. However, it is also assumed and experimentally observed that $\tau_{0}$ of the CM is descriptive for the JohariGoldstein $\beta$ relaxation (JG $\beta$ ), which involves the motion of entire molecules (or parts thereof) and likely appears in local regions in internal equilibrium in the glass. ${ }^{49}$ These assumptions, along with the observed correlation in this study, raise the following question: how exactly is surface mobility linked to JG $\beta$ ? Further surface mobility studies, in proximity to temperatures linked to the relaxation process, might be beneficial. However, their practicality remains questionable because of the increased timeframes associated with the decrease in diffusion at low temperatures.

\section{CONCLUSIONS}

The current study demonstrates the ability of already low amounts of the polymer SP $(1 \%(\mathrm{w} / \mathrm{w}))$ to significantly slow down molecular mobility on the surface of supersaturated IMC ASDs. A further increase in SP concentration results in a turnover point between 2.5 and $5 \%(\mathrm{w} / \mathrm{w}) \mathrm{SP}$, where the inhibiting effect of the polymer on the surface diffusion 
becomes less pronounced. We suggest a polymer dominated diffusion with the less mobile polymer chains on the surface of the ASD to slow down molecular mobility of IMC and thus inhibit the recrystallization of amorphous IMC. The observed change in lateral molecular surface diffusivity correlates well with a significant increase in physical stability of the studied supersaturated ASDs, as seen by the delay in the onset of recrystallization from 6 weeks $(2.5 \%(\mathrm{w} / \mathrm{w}) \mathrm{SP})$ to 9 months $(5 \%(w / w)$ SP). We therefore identify the reduction in diffusivity on the surface of the supersaturated ASD as a major stabilizing factor, as no significant increase in $T_{\mathrm{g}}$ or disruption of IMC clusters is observed for low SP concentration. The study underlines the importance of surface related properties, such as lateral molecular mobility, for the physical stability of amorphous drugs and ASDs, respectively.

From an applied standpoint, the study further highlights the practicality of using a miniaturized AFM and Mullins' model to enable cost-effective and user-friendly measurements of molecular mobility on amorphous surfaces, opening the door for future application areas.

\section{ASSOCIATED CONTENT}

\section{SI Supporting Information}

The Supporting Information is available free of charge at https://pubs.acs.org/doi/10.1021/acs.molpharmaceut.0c00176.

Decay mechanisms of Mullins' model, experimental details, determination of drug-polymer solubility using Flory-Huggins model, FTIR spectra, Gordon-Taylor comparison, calculation of $D_{s}$, physical stability and XRPD diffractograms (PDF)

\section{AUTHOR INFORMATION}

\section{Corresponding Author}

Thomas Rades - Department of Pharmacy, University of Copenhagen, 2100 København Ø, Denmark; 이이.org/ 0000-0002-7521-6020; Email: thomas.rades@sund.ku.dk

\section{Authors}

Jacob Bannow - Department of Pharmacy, University of Copenhagen, 2100 København Ø, Denmark

Maximilian Karl - Department of Pharmacy, University of Copenhagen, 2100 København Ø, Denmark; @ orcid.org/ 0000-0002-3946-0317

Peter Emil Larsen - Department of Health Technology, Technical University of Denmark, 2800 Kongens Lyngby, Denmark

En Te Hwu - Department of Health Technology, Technical University of Denmark, 2800 Kongens Lyngby, Denmark; () orcid.org/0000-0002-5971-4978

Complete contact information is available at: https://pubs.acs.org/10.1021/acs.molpharmaceut.0c00176

\section{Author Contributions \\ ${ }^{\S}$ These authors contributed equally to this work. \\ Notes}

The authors declare no competing financial interest.

\section{ACKNOWLEDGMENTS}

The Lundbeck Foundation (Grant No. R218-2016-1252) is acknowledged for financial support. This research further received funding from the Danish National Research
Foundation (DNRF122) and Villum Fonden (Grant No. 9301).

\section{REFERENCES}

(1) Ditchfield, R; Llera-Rodríguez, D.; Seebauer, E. G. Semiconductor surface diffusion: Nonthermal effects of photon illumination. Phys. Rev. B: Condens. Matter Mater. Phys. 2000, 61 (20), 13710-13720.

(2) J.J, F.; H, V. D. Surface Mobility in Chemical Reactions and Catalysis. In Surface Mobilities on Solid Materials; Springer: Boston, MA, 1983; Vol. 86.

(3) Ruan, S.; Zhang, W.; Sun, Y.; Ediger, M. D.; Yu, L. Surface diffusion and surface crystal growth of tris-naphthyl benzene glasses. J. Chem. Phys. 2016, 145 (6), 064503.

(4) Zhu, L.; Yu, L. Generality of forming stable organic glasses by vapor deposition. Chem. Phys. Lett. 2010, 499 (1-3), 62-65.

(5) Descamps, M. Amorphous Pharmaceutical Solids. Adv. Drug Delivery Rev. 2016, 100, 1-2.

(6) Craig, D. Q. M.; Royall, P. G.; Kett, V. L.; Hopton, M. L. The relevance of the amorphous state to pharmaceutical dosage forms: glassy drugs and freeze dried systems. Int. J. Pharm. 1999, 179 (2), 179-207.

(7) Laitinen, R.; Löbmann, K.; Strachan, C. J.; Grohganz, H.; Rades, T. Emerging trends in the stabilization of amorphous drugs. Int. J. Pharm. 2013, 453 (1), 65-79.

(8) Zhu, L.; Brian, C. W.; Swallen, S. F.; Straus, P. T.; Ediger, M. D.; Yu, L. Surface self-diffusion of an organic glass. Phys. Rev. Lett. 2011, 106 (25), 256103.

(9) Dengale, S. J.; Grohganz, H.; Rades, T.; Lobmann, K. Recent advances in co-amorphous drug formulations. Adv. Drug Delivery Rev. 2016, 100, 116-25.

(10) Qian, K. K.; Bogner, R. H. Application of Mesoporous Silicon Dioxide and Silicate in Oral Amorphous Drug Delivery Systems. J. Pharm. Sci. 2012, 101 (2), 444-463.

(11) Leuner, C.; Dressman, J. Improving drug solubility for oral delivery using solid dispersions. Eur. J. Pharm. Biopharm. 2000, 50 (1), 47-60.

(12) Qian, F.; Huang, J.; Hussain, M. A. Drug-Polymer Solubility and Miscibility: Stability Consideration and Practical Challenges in Amorphous Solid Dispersion Development. J. Pharm. Sci. 2010, 99 (7), 2941-2947.

(13) Lehmkemper, K.; Kyeremateng, S. O.; Heinzerling, O.; Degenhardt, M.; Sadowski, G. Long-Term Physical Stability of PVP- and PVPVA-Amorphous Solid Dispersions. Mol. Pharmaceutics 2017, 14 (1), 157-171.

(14) Van den Mooter, G.; Wuyts, M.; Blaton, N.; Busson, R.; Grobet, P.; Augustijns, P.; Kinget, R. Physical stabilisation of amorphous ketoconazole in solid dispersions with polyvinylpyrrolidone K25. Eur. J. Pharm. Sci. 2001, 12 (3), 261-269.

(15) Matsumoto, T.; Zografi, G. Physical Properties of Solid Molecular Dispersions of Indomethacin with Poly(vinylpyrrolidone) and Poly(vinylpyrrolidone-co-vinyl-acetate) in Relation to Indomethacin Crystallization. Pharm. Res. 1999, 16 (11), 1722-1728.

(16) Xie, T.; Taylor, L. S. Effect of Temperature and Moisture on the Physical Stability of Binary and Ternary Amorphous Solid Dispersions of Celecoxib. J. Pharm. Sci. 2017, 106 (1), 100-110.

(17) Ehrlich, G.; Stolt, K. Surface Diffusion. Annu. Rev. Phys. Chem. 1980, 31 (1), 603-637.

(18) Keeffe, M. E.; Umbach, C. C.; Blakely, J. M. Surface selfdiffusion on $\mathrm{Si}$ from the evolution of periodic atomic step arrays. $J$. Phys. Chem. Solids 1994, 55 (10), 965-973.

(19) Seebauer, E. G.; Allen, C. E. Estimating surface diffusion coefficients. Prog. Surf. Sci. 1995, 49 (3), 265-330.

(20) Mapes, M. K.; Swallen, S. F.; Ediger, M. D. Self-Diffusion of Supercooled o-Terphenyl near the Glass Transition Temperature. J. Phys. Chem. B 2006, 110 (1), 507-511.

(21) Brian, C. W.; Yu, L. Surface Self-Diffusion of Organic Glasses. J. Phys. Chem. A 2013, 117 (50), 13303-13309. 
(22) Chen, Y.; Zhang, W.; Yu, L. Hydrogen Bonding Slows Down Surface Diffusion of Molecular Glasses. J. Phys. Chem. B 2016, 120 (32), 8007-8015.

(23) Huang, C.; Ruan, S.; Cai, T.; Yu, L. Fast Surface Diffusion and Crystallization of Amorphous Griseofulvin. J. Phys. Chem. B 2017, 121 (40), 9463-9468.

(24) Zhang, W.; Yu, L. Surface Diffusion of Polymer Glasses. Macromolecules 2016, 49 (2), 731-735.

(25) Zhang, W.; Teerakapibal, R.; Yu, L. Surface Mobility of Amorphous o-Terphenyl: A Strong Inhibitory Effect of LowConcentration Polystyrene. J. Phys. Chem. B 2016, 120 (27), 68426847.

(26) Mullins, W. W. Flattening of a Nearly Plane Solid Surface due to Capillarity. J. Appl. Phys. 1959, 30 (1), 77-83.

(27) Capaccioli, S.; Ngai, K. L.; Paluch, M.; Prevosto, D. Mechanism of fast surface self-diffusion of an organic glass. Phys. Rev. E 2012, 86 (5), 051503.

(28) Castez, M. F. Surface-diffusion-driven decay of patterns: beyond the small slopes approximation. J. Phys.: Condens. Matter 2010, 22 (34), 345007.

(29) Chai, Y.; Salez, T.; McGraw, J. D.; Benzaquen, M.; DalnokiVeress, K.; Raphaël, E.; Forrest, J. A. A Direct Quantitative Measure of Surface Mobility in a Glassy Polymer. Science 2014, 343 (6174), 994-999.

(30) Knopp, M. M.; Tajber, L.; Tian, Y.; Olesen, N. E.; Jones, D. S.; Kozyra, A.; Lobmann, K.; Paluch, K.; Brennan, C. M.; Holm, R.; Healy, A. M.; Andrews, G. P.; Rades, T. Comparative Study of Different Methods for the Prediction of Drug-Polymer Solubility. Mol. Pharmaceutics 2015, 12 (9), 3408-19.

(31) Blaabjerg, L. I.; Bulduk, B.; Lindenberg, E.; Löbmann, K.; Rades, T.; Grohganz, H. Influence of Glass Forming Ability on the Physical Stability of Supersaturated Amorphous Solid Dispersions. J. Pharm. Sci. 2019, 108 (8), 2561-2569.

(32) Chen, Y.; Chen, Z.; Tylinski, M.; Ediger, M. D.; Yu, L. Effect of molecular size and hydrogen bonding on three surface-facilitated processes in molecular glasses: Surface diffusion, surface crystal growth, and formation of stable glasses by vapor deposition. J. Chem. Phys. 2019, 150 (2), 024502.

(33) Vasanthavada, M.; Tong, W.-Q.; Joshi, Y.; Kislalioglu, M. S. Phase Behavior of Amorphous Molecular Dispersions II: Role of Hydrogen Bonding in Solid Solubility and Phase Separation Kinetics. Pharm. Res. 2005, 22 (3), 440-448.

(34) Strachan, C. J.; Rades, T.; Gordon, K. C. A theoretical and spectroscopic study of $\gamma$-crystalline and amorphous indometacin. $J$. Pharm. Pharmacol. 2007, 59 (2), 261-269.

(35) Lin, S.-Y.; Lin, H.-L.; Chi, Y.-T.; Huang, Y.-T.; Kao, C.-Y.; Hsieh, W.-H. Thermoanalytical and Fourier transform infrared spectral curve-fitting techniques used to investigate the amorphous indomethacin formation and its physical stability in IndomethacinSoluplus ${ }^{\circledR}$ solid dispersions. Int. J. Pharm. 2015, 496 (2), 457-465.

(36) Yuan, X.; Xiang, T.-X.; Anderson, B. D.; Munson, E. J. Hydrogen Bonding Interactions in Amorphous Indomethacin and Its Amorphous Solid Dispersions with Poly(vinylpyrrolidone) and Poly(vinylpyrrolidone-co-vinyl acetate) Studied Using 13C SolidState NMR. Mol. Pharmaceutics 2015, 12 (12), 4518-4528.

(37) Taylor, L. S.; Zografi, G. Spectroscopic Characterization of Interactions Between PVP and Indomethacin in Amorphous Molecular Dispersions. Pharm. Res. 1997, 14 (12), 1691-1698.

(38) Chiou, W. L.; Riegelman, S. Pharmaceutical Applications of Solid Dispersion Systems. J. Pharm. Sci. 1971, 60 (9), 1281-1302.

(39) Baird, J. A.; Taylor, L. S. Evaluation of amorphous solid dispersion properties using thermal analysis techniques. Adv. Drug Delivery Rev. 2012, 64 (5), 396-421.

(40) Dengale, S. J.; Ranjan, O. P.; Hussen, S. S.; Krishna, B. S. M.; Musmade, P. B.; Gautham Shenoy, G.; Bhat, K. Preparation and characterization of co-amorphous Ritonavir-Indomethacin systems by solvent evaporation technique: Improved dissolution behavior and physical stability without evidence of intermolecular interactions. Eur. J. Pharm. Sci. 2014, 62, 57-64.
(41) Caron, V.; Hu, Y.; Tajber, L.; Erxleben, A.; Corrigan, O. I.; McArdle, P.; Healy, A. M. Amorphous Solid Dispersions of Sulfonamide/Soluplus ${ }^{\circledR}$ and Sulfonamide/PVP Prepared by Ball Milling. AAPS PharmSciTech 2013, 14 (1), 464-474.

(42) Shamblin, S. L.; Taylor, L. S.; Zografi, G. Mixing behavior of colyophilized binary systems. J. Pharm. Sci. 1998, 87 (6), 694-701.

(43) Hancock, B. C.; Zografi, G. The Relationship Between the Glass Transition Temperature and the Water Content of Amorphous Pharmaceutical Solids. Pharm. Res. 1994, 11 (4), 471-477.

(44) Swallen, S. F.; Ediger, M. D. Self-diffusion of the amorphous pharmaceutical indomethacin near Tg. Soft Matter 2011, 7 (21), 10339-10344.

(45) Yoshioka, M.; Hancock, B. C.; Zografi, G. Crystallization of Indomethacin from the Amorphous State below and above Its Glass Transition Temperature. J. Pharm. Sci. 1994, 83 (12), 1700-1705.

(46) Andronis, V.; Yoshioka, M.; Zografi, G. Effects of sorbed water on the crystallization of indomethacin from the amorphous state. J. Pharm. Sci. 1997, 86 (3), 346-351.

(47) Powell, C. T.; Xi, H.; Sun, Y.; Gunn, E.; Chen, Y.; Ediger, M. D.; Yu, L. Fast Crystal Growth in o-Terphenyl Glasses: A Possible Role for Fracture and Surface Mobility. J. Phys. Chem. B 2015, 119 (31), 10124-30.

(48) Kissi, E. O.; Grohganz, H.; Löbmann, K.; Ruggiero, M. T.; Zeitler, J. A.; Rades, T. Glass-Transition Temperature of the $\beta$ Relaxation as the Major Predictive Parameter for Recrystallization of Neat Amorphous Drugs. J. Phys. Chem. B 2018, 122 (10), 28032808.

(49) Johari, G. P. Source of JG-Relaxation in the Entropy of Glass. J. Phys. Chem. B 2019, 123 (13), 3010-3023. 